\title{
ANTERIOR SACRAL MENINGOCELE CONTAINING LARGE DERMOID CYST: A CASE REPORT.
}

\author{
D. B. Katikar, R. D. Jaykar, P. Kasabe, S. Jadhav, R. R. Ghule.
}
1. Assistant Professor \& Neurosurgeon. Department of General Surgery, Dr. VM GMC, Solapur, Maharashtra. India.
2. Associate Professor. Department of General Surgery, Dr. VM GMC, Solapur, Maharashtra. India.
3. Assistant Professor. Department of General Surgery, Dr. VM GMC, Solapur, Maharashtra. India.
4. Assistant Professor. Department of General Surgery, Dr. VM GMC, Solapur, Maharashtra. India.
5. Resident. Department of General Surgery, Dr. VM GMC, Solapur, Maharashtra. India.

\section{CORRESPONDING AUTHOR:}

Rahul R. Ghule, At post Vilegaon, Tq. Karanja lad, Dist: Washim , Maharashtra, 444110.

E-mail: ghulerahul1234@rediffmail.com

ABSTRACT: 24 years female patient was referred from gynaecology department as a case of mass in pelvis. She was initially investigated for primary infertility in same department. Ultrasonography of abdomen was suggestive of teratoma. Contrast enhanced CT scan of abdomen and pelvis was suggestive of anterior sacral meningocele with scimitar sacral deformity. CT scan findings were confirmed by MRI. Patient underwent excision of anterior meningocele via posterior trans-sacral approach. Intraoperatively, we found huge dermoid cyst within meningocele. Findings latter on confirmed by histopathology. Postoperatively patient recovered without any complications and was discharged on day 10.

KEY WORDS: Anterior sacral meningocele, dermoid cyst, scimitar sacral deformity.

INTRODUCTION: Anterior Sacral Meningocele (ASM) is a rare congenital anomaly which was first described in 1837 by Bryant. Anterior Sacral Meningocele is a unilocular or multilocular extension or herniation of the dura mater and arachnoid out of the sacral spinal canal through a defect in the sacrum into the retroperitoneum and infraperitoneal space, either anteriorly through the body of the sacrum or anterolaterally through an enlarged intervertebral foramen or coalesced foramina. It contains Cerebrospinal fluid (CSF), which in some reported cases, has been discoloured (slightly yellow), and had an elevated protein content. The incidence of a posterior meningocele has been reported to be about 1/ 1,000 live births, but the actual incidence of Anterior Sacral Meningocele is unknown due to the asymptomatic characteristics. It is recognised within the heritable Currarino triad; consisting of congenital anal stenosis, scimitar sacrum and a presacral mass. However, anterior sacral meningocele may exist without the presence of anal stenosis. Anterior Sacral Meningocele has been associated with a variety of congenital abnormalities of the pelvis. Some of these abnormalities include; anorectal malformations, dermoid cysts, sacrococcygeal teratoma and lipoma, duplication of urogenital tracts as well as epidermoid tumours. Number of reports have shown some association with Marfan syndrome and with neurofibromatosis.

CASE REPORT: 24 years female referred from gynaecology department to surgery OPD as a case of primary infertility due to pelvic mass as given in ultrasonography of abdomen and 
pelvis. She also had complaint of intermittent constipation. No history of urinary complaints, menstrual complaints, (previous cycles were regular), abdominal distention, vomiting, pain in abdomen and pain while defecation. Personal history- married since 1.5 years. On examination her vitals were stable. On per abdominal findings there was a vague lump in lower abdomen deep in pelvis. On per rectal examination there was firm bulge on the posterior wall of rectum with lower margin and lateral margins distinct \& upper margin could not be felt. Rectal mucosa was normal. On investigation complete blood count was normal. X-ray pubis with both hips suggestive of scimitar sacral deformity. Ultrasonography of pelvis shows well defined cystic mass of size $11.6 \mathrm{~cm} \times 11.2 \mathrm{~cm}$ filled with internal echoes\& adherent to presacral region suggestive of ,? Teratoma. Contrast enhanced CT scan of abdomen and pelvis suggestive of, $12.5 \mathrm{~cm} \times 11.4 \mathrm{~cm} \times 9.9 \mathrm{~cm}$ sized well defined, thin walled, non enhancing cystic lesion seen in pelvis within presacral (retro rectal) space and is in communication with neural foramina through smooth inverted crescentic defect in sacrum anteriorly at level of S2, S3, S4 vertebra predominantly on right side. Mass causing forward displacement of uterus, urinary bladder, s/o anterior sacral meningocele.

After review of literature, we learn that , because of rarity of lesion both modality i.e., CT \& MRI reported as meningocele. As they thought, the communication was seen and lesion was in continuity with subarachnoid space. The investigation of choice would have been CT MYELOGRAPHY to confirm or rule out communication between the spinal subarachnoid space \& lesion. Hence we considered anterior meningocele as the possible diagnosis and patient was posted for excision via posterior trans-sacral route

PROCEDURE : Midline incision taken, paraspinal muscle separated, lamina were exposed from L3 to S2 and L4,5, S2 laminectomy done. Dura mater was opened. There was solid lesion ie., dermoid cyst which was excised. It was sitting in the neck of anterior meningocele. Once the solid part was removed, milky white liquid about 1200 cc was aspirated. In anterior meningocele, the choice of treatment is ligating the neck of sac after aspirating the contents. It was not practical here as the content of dermoid would have gone on accumulating in the sac. The sac was excised from the connection to duramater and by combination of blunt dissection with finger and sharp dissection through the anterior sacral defect it was totally excised with taking care not to injure surrounding pelvic structures. Then dura mater closed watertight and wound was closed in layers. Post operative per rectal and vaginal examination did no revealed any injury. On postoperative day 10 , suture removed and patient was discharged.

DISCUSSION: Retro rectal cystic lesions in adults are rare, and most cases are congenital. Developmental cysts are the most common congenital entity encountered in the retro rectal space and include epidermoid cysts, dermoid cysts, and enteric cysts. There are two types of enteric cysts, tailgut cysts (so-called retro rectal cyst-hamartomas or mucin-secreting cysts) and cystic rectal duplication. Neurenteric cysts have also been reported. Developmental cysts are defined by their histologic components and retro rectal location, lying anterior to the sacrum and posterior to the rectum. They occur mostly in middle-aged women and in 3:1 female-to-male ratio. The most important complications of these cysts are infection with a secondary fistula and malignant degeneration of enteric cysts. The differential diagnosis includes a wide variety of conditions that occur in the retro rectal space: cystic sacrococcygeal teratoma, anterior sacral meningocele, anal duct or gland cyst, necrotic rectal leiomyosarcoma, extraperitoneal adenomucinosis, cystic lymphangioma, pyogenic abscess, neurogenic cyst, and 
necrotic sacral chordoma. The clinical presentation is variable, depending on the size and therefore mass effect of the developmental cyst and the presence of infection in the cyst. It has been estimated that $50 \%$ of developmental cysts are asymptomatic, being discovered during routine physical examination or ultrasonography (US). Symptoms are often related to local compression on the rectum, which causes constipation, rectal fullness, painful defecation, and lower abdominal pain, and to local compression on the lower urinary tract, which causes dysuria and urinary frequency. The three major complications of developmental cysts that are appropriate indications for intervention are infection, bleeding, and malignant degeneration. In the present case infertility was one of the associated chief complaint for which she came for medical checkup.

\section{REFFERENCE:}

1. RiteshKansal, AmitMahore, NitinDange, Sanjay Kukrej a.Epidermoid Cyst Inside Anterior Sacral Meningocele in an Adult Patient of Currarino Syndrome Manifesting with Meningitis, Turkish Neurosurgery 2012, Vol: 22, No: 5, 659661Turkish Neurosurgery 2012, Vol: 22, No: 5, 659-661.

2. Shamoto H, Yoshida Y, Shirane R, Yoshimoto T: Anterior sacralmeningocelecompletely occupied by an epidermoidtumor. Childs NervSyst 15:209-211, 1999.

3. Currarino G, Coln D, Votteler T: Triad of anorectal, sacral andpresacral anomalies. Am J Roentgenol 137:395-398, 1981.4)

4. Martina Džoić1*, Jana Fila2, Mislav Čavka3, Mirjana Vukelić-Marković3, Boris Brkljačić3.Epidermoid cyst in presacral space,medicinafluminensis 2011, Vol. 47, No. 3, p. 312-315.5)

5. Ranson JHC, Harris MN. Retrorectalepidermoid cyst. Diseases of the colon \& rectum 1968;12:26-9.

6. Yang DM, Yoon MH, Kim HS, Kim HS, Chung S, Chung JW et al. CT and MR findings of presacralepidermoid cyst. J Korean RadiolSoc 1999;41:545-7.

7. Wilkins R H. Lateral and anterior spinal meningoceles in Wilkins R H, Regachary SS eds Neurosurgery, 2nd Edn McGraw-Hill, New York 1996, 3521-3525.

8. Kuronski M, Kurosaki M, Kamitani H, Anno Y, Watanabe T, Tomokatsu H, Yamasaki T. Complete familial Currarino triad. J Neurosurgery (Spine 1) 2001; 94: 158-161

9. Rigante D and Segui C. Anterior sacral meningocele in a patient with marfan syndrome. ClinNeuropathol 2001; 20: 70-72.

10. Andersen C, Tange M, Bjerre P. Anterior sacral meningocele occurring in one family. An autosomal dominantly inherited condition. Br J Neurosurg 1990; 4: 59 - 62

11. Cohn J, Bay-Nielsen E. Hereditary defect of the sacrum and coccyx with anterior sacral meningocele. ActaPaediatrScand 1969; 58: 268- 274

12. Somuncu S, Ariturk E, Iyigun O, Bernay F, Rizalar R, Gunaydin M, Gurses N. A case of anterior sacral menigocele excised using the posterior sagittal approach. J PaediatrSurg 1997; 32: 730- 732.

13. Kochling J et.al. The Currarino syndrome - Hereditary transmitted syndrome of anorectal, sacral, and presacral anomalies.Case report and review of the literature.1996, Eur.J.Pediatr.Surg.6; 114 -119.

14. Somuncu S. Ariturk E. Iyigun O. Bernay F. Rizalar R. Gunaydin M. and Gurses N. (1997) A case of anterior sacral meningocele totally excised using the posterior sagittal approach. J. Pediatr. Surg. 32; 730 - 732. 
15. Bennett EU, Johnson RJ. Presacraltumors and cysts in adults. Diseases of the colon \& rectum 1975;18:581-96.

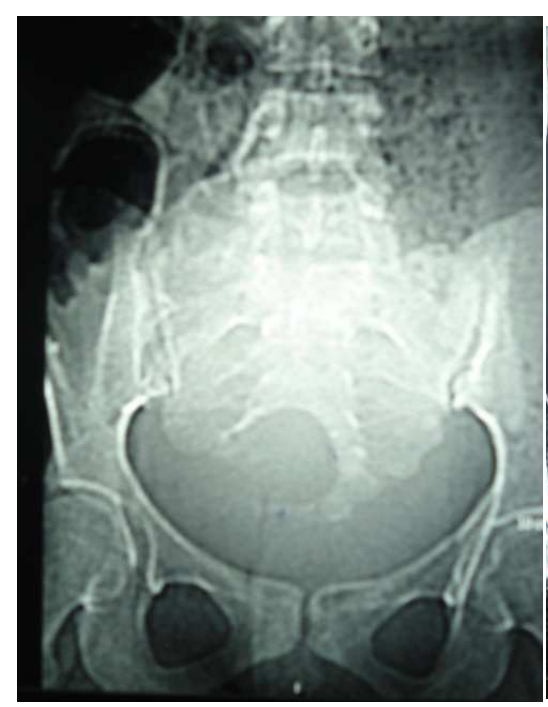

Fig 1: Scanogram (CT)

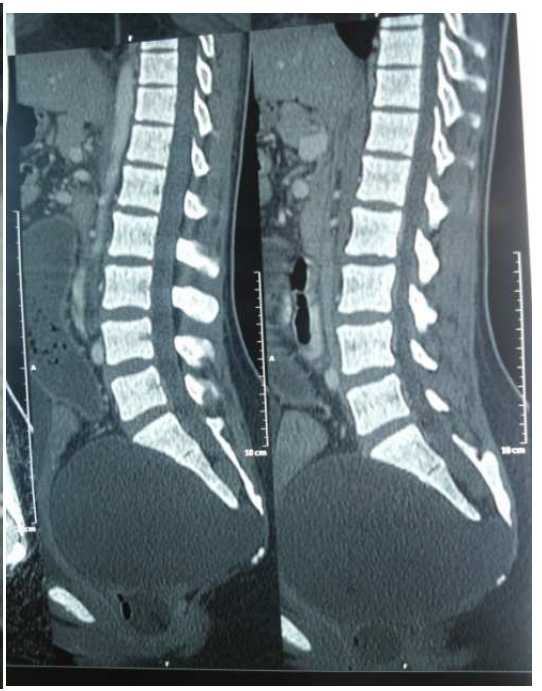

Fig2 Sagittal view (reconstructed image)

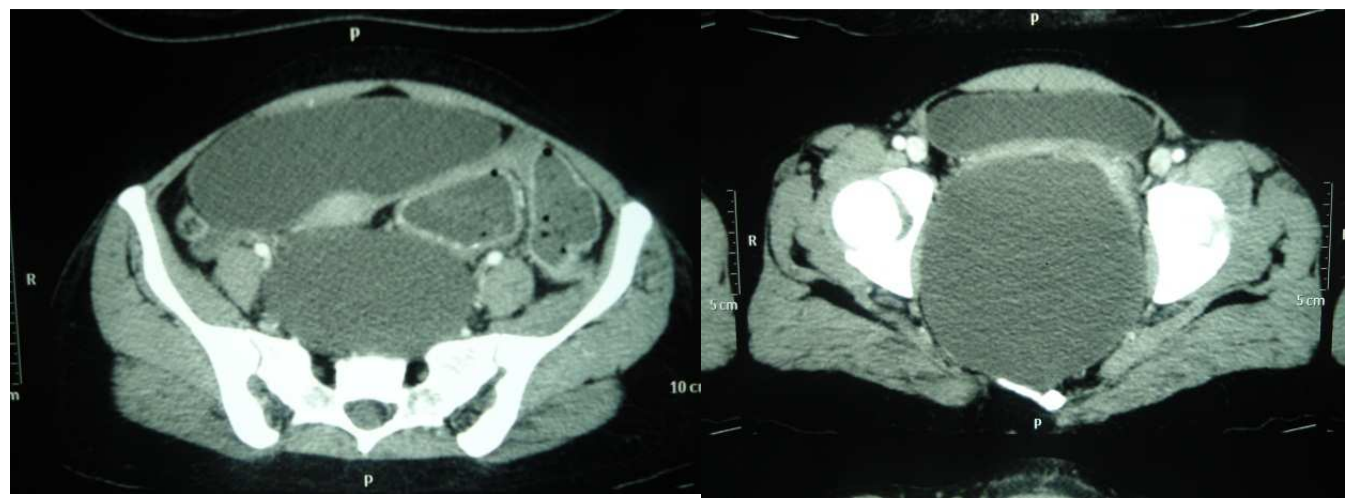

Fig3: axial view

Fig 4: axial view

MRI spine was suggestive of large anterior sacral menigocele of size $12.2 \mathrm{~cm} \mathrm{X} 9 \mathrm{~cm} \mathrm{X} 11.3 \mathrm{~cm}$ in presacral space causing mass effect with partial sacral agenesis. Evidence of $2^{\text {nd }}$ intrasacralmeningocele of size $3.4 \times 1.4 \mathrm{~cm}$ in sacral canal at $\mathrm{S} 1 \& \mathrm{~S} 2$. Evidence of small oval shaped lesion of size $1.4 \mathrm{~cm}$ on dorsal aspect of S2 body in sacral canal on left side suggestive of ? Epidermoid cyst. 
CASE REPORT

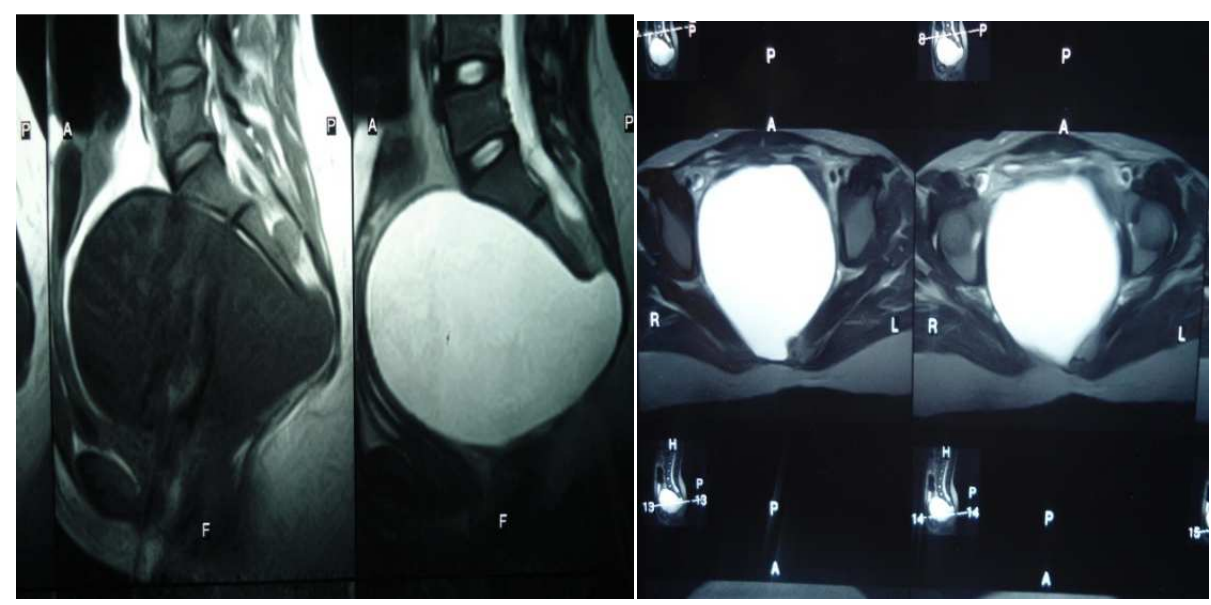

Fig 5: MRI dorsolumbar spine sagittal and axial view.
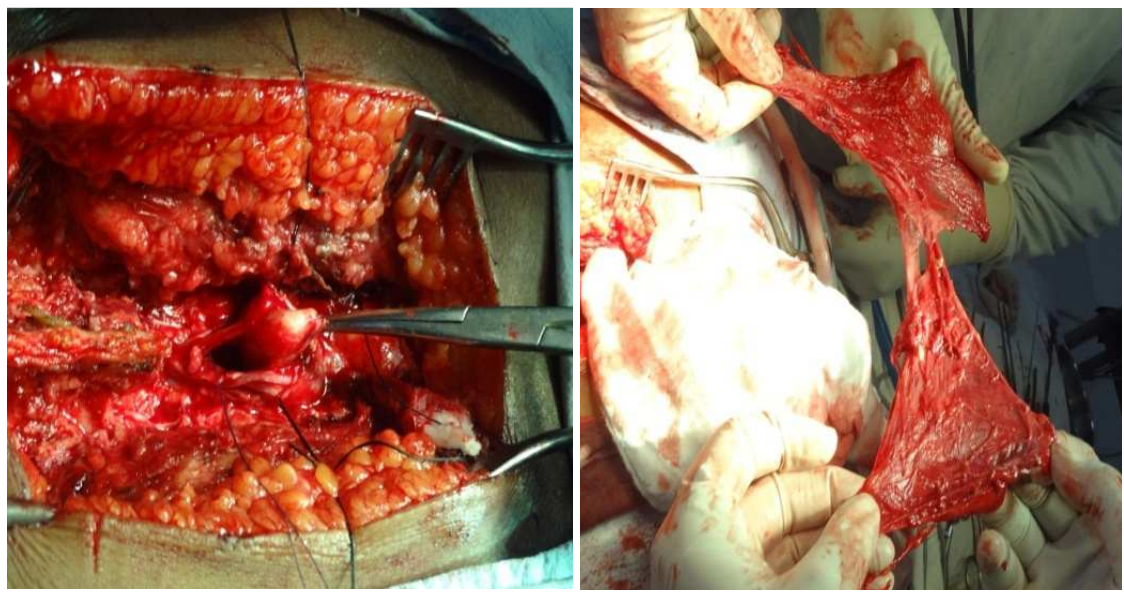

Fig 6: Images showing intradural dermoid cyst and after removal of complete sac.

Fig 7: Postoperative defect and sac of specimen.
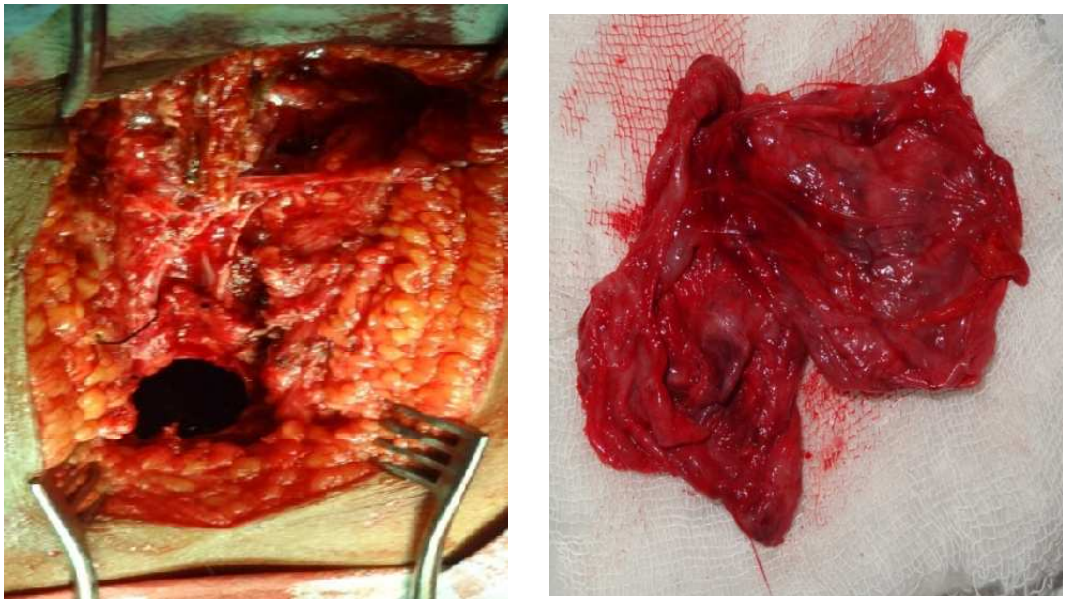


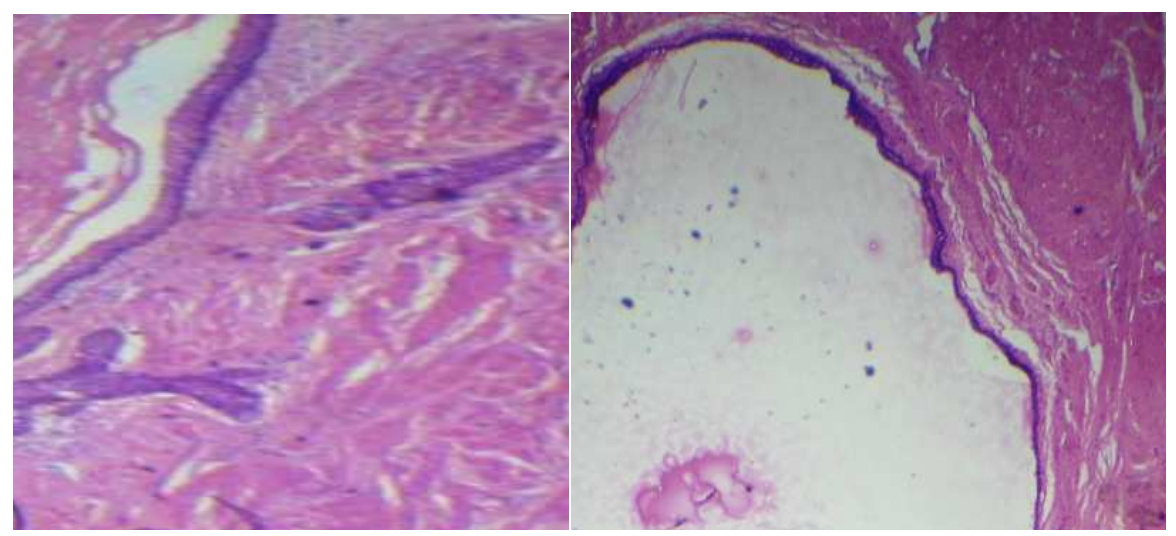

Fig 8: Histopathological examination suggestive of dermoid cyst.

Patient had a huge cystic cavity in the pelvis lying behind the rectum anterior to sacrum. We had operated from the sacral defect and with help of blunt and sharp dissection, we had removed sac in toto without any tear in the fundus of sac.

Literature says operating through perineal or transperitoneal approach, the incidence of infection and postoperative morbidity is very high.

This was huge cystic mass and because of proximity to thecal sac and occuward position of the pelvic cavity, we have not put any drain. This might have resulted in serous collection in redundant space occupied by the tumour. The present collection which is $\left(1 / 5^{\text {th }}\right.$ of preoperative size of dermoid cyst ) appears to be postoperative serous collection and is likely to get absorbed over period of time.

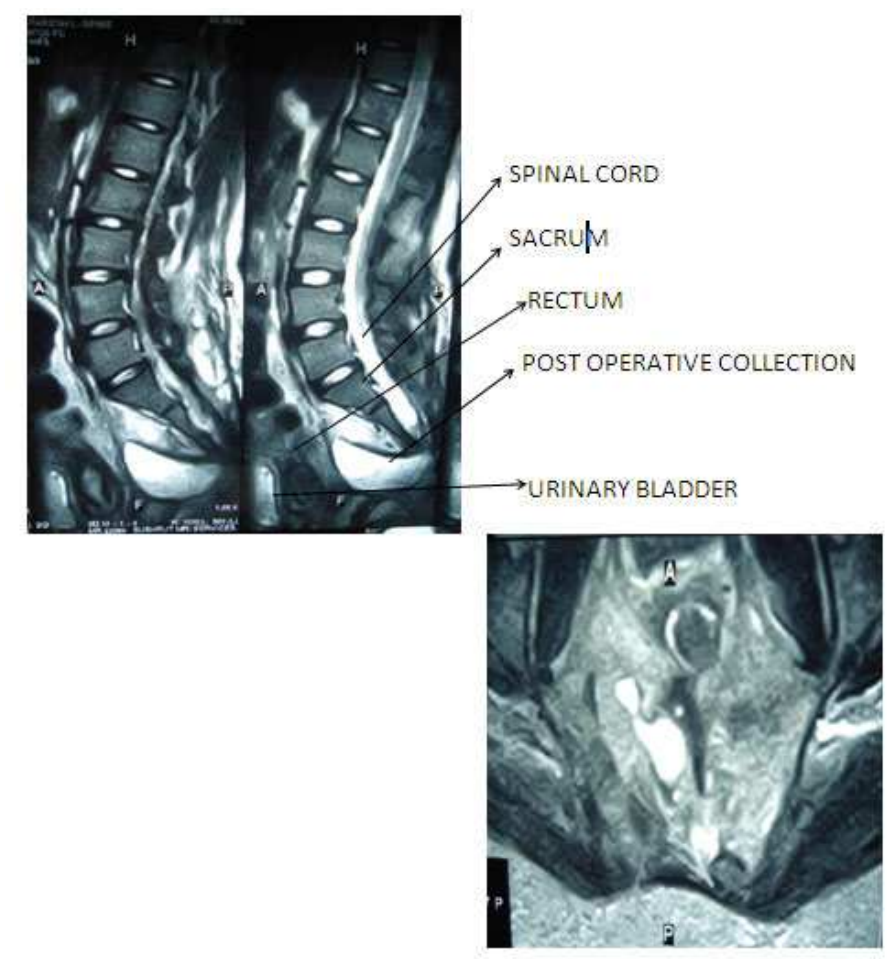

Fig no. 9: sagittal \& axial view of post operative MRI spine respectively. 